DOI: 10.34185/1991-7848.itmm.2020.01.001

\title{
СИМУЛЯЦИЯ ВЛИЯНИЯ ОСТАТОЧНЫХ НАПРЯЖЕНИЙ И ПАРАМЕТРОВ SLM-ТЕХНОЛОГИИ НА ФОРМИРОВАНИЕ ОБЛАСТИ ГРАНИЦ ИЗДЕЛИЯ ИЗ ЖАРОПРОЧНОГО НИКЕЛЕВОГО СПЛАВА INCONEL 718
}

Аджармский С.В. ${ }^{1,2}$, Кононенко А.А. ${ }^{2,3}$, к.т.н., Подольский Р.В. ${ }^{2,3,4}$

${ }^{1}$ Днепропетровский национальный университет им. О. Гончара, Украина, Днепр

${ }^{2} L L C$ «Additive Laser Technology of Ukraine», Украина, Днепр, info@alt-print.com

${ }^{3}$ Институт черной металлургии им. 3.И. Некрасова НАН Украины, Днепр ${ }^{4}$ Национальная металлургическая академия Украины, Украина, Днепр

Аннотация. Селективное лазерное плавление (SLM) - это технология аддитивного производства при которой с помощью лазера можно изготавливать детали со сложной геометрией и высокими механическими свойствами. Однако, оптимальные технологические параметры SLM-процесса для металлических материалов сложно предсказать. Представлены результаты универсальной и упрощенной модели для прогнозирования плотности энергии в области границ металлической детали из Inconel 718 , для предотвращения отклонений в геометрии детали на основе соотношения между плотностью подводимой удельной энергии и ее поглощением во время процесса.

Ключевые слова: АДДИТИВНОЕ ПРОИЗВОДСТВО, ЛАЗЕР, ГЕОМЕТРИЯ, СИМУЛЯЦИЯ, INCONEL 718.

Аддитивное производство заключается в построении твердого объекта путем многократного добавления тонких слоев поверх ранее сделанных. При селективном лазерном плавлении (SLM-технология) металл подвергается воздействию лазера, что приводит к его плавлению. Когда металл остывает, возникают напряжения сжатия, которые могут приводить к изменению первоначальной формы (коробление) изделия.

Модуль моделирования сил сжатия - это инструмент на платформе Magics, который дает важную обратную связь пользователю о производстве детали с помощью SLM-технология для корректировки положения и ориентации детали, а также параметров опор (поддержек). 
International scientific and technical conference Information Technologies in Metallurgy and Machine building - ITMM 2020

Моделирование основано на воксельной структуре детали. Воксель (Voxel) (объемный пиксель) - это кубическая единица, составляющая трехмерный объект. Это минимальная обрабатываемая единица трехмерной матрицы, и ее можно рассматривать как эквивалент пикселя в двумерном объекте. Модуль моделирования рассматривает внешнюю поверхность детали как стопку кубов.

На платформе Magics процесс симуляции построен на основе воксельной структуры, представленной на рис. 1. Показан процесс возникновения остаточных напряжений при наложении новых слоев. Последний слой сжимается, и он деформируется, загибая края внутрь. Нижние слои изделия показаны на рис. 1 над опорой синего цвета.

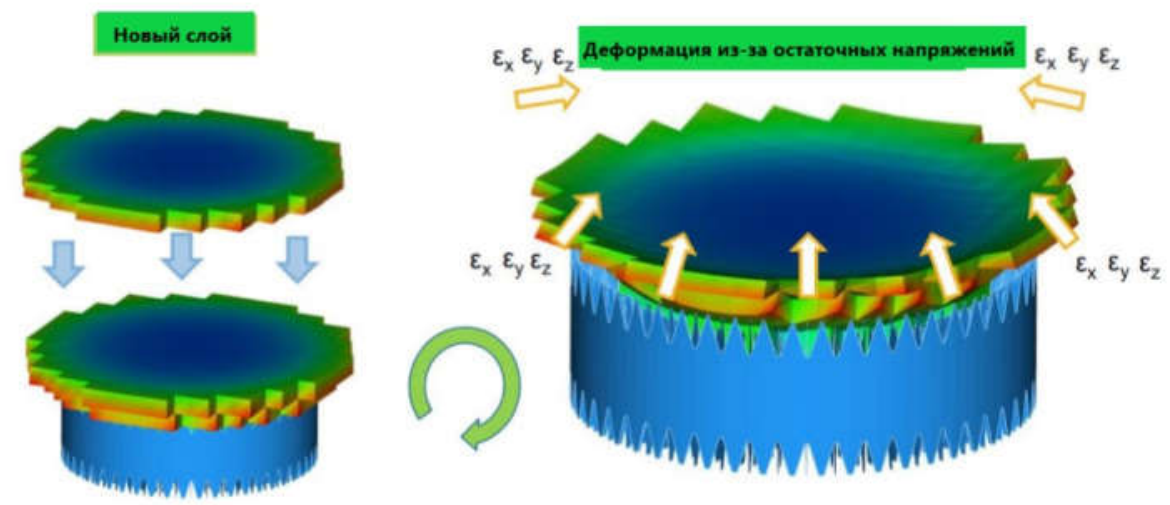

Рисунок 1 - Симуляция остаточных напряжений на платформе Magics при наложении нового слоя изделия с цилиндрической формой на поддержках

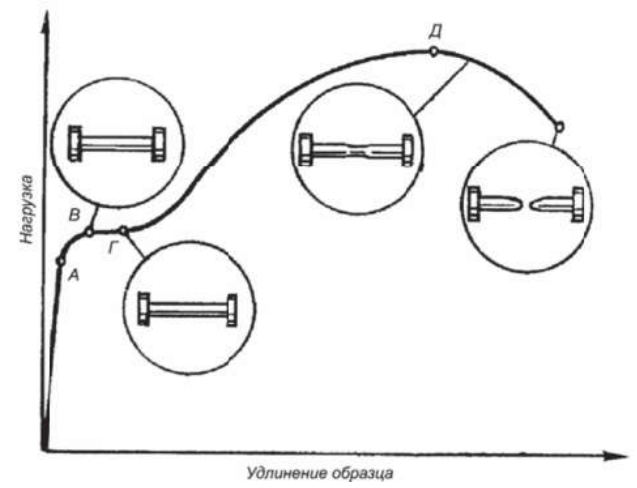

Рисунок 2 - Техническая диаграмма растяжения [1]

При воздействии растягивающих напряжений поведение материала может быть представлено в виде кривой (рис. 2) (техническая диаграмма растяжения), показывающей взаимосвязь между удлинением и напряжением. Изначально Inconel 718 при симуляции демонстрирует линейную зависимость напряжение-деформация до предела текучести. До этого момента тело может вернуться к своей первоначальной форме и размеру, когда растягивающая 
Ministry of Education and Science of Ukraine

The National Metallurgical Academy of Ukraine, Dnipro, 17 - 19 March, 2020

нагрузка устранена. Когда напряжения превышают предел текучести, Inconel 718 демонстрирует пластическое поведение, характеризуемое невосстановимой пластической деформацией, и зависимость деформации от напряжения становится нелинейной. До разрушения возможна большая деформация. Наконец, будет точка разрыва, когда напряжение приведет к разрушению материала.

В результате моделирования могут быть получены различные функции:

- Смещение: в этом разделе показана деформация объекта по отношению к его исходной геометрии в мм.

- Общий: в этом разделе можно найти следующие переменные поля: элементы ошибок, относительная плотность и дробная доля.

- Опасность задирания краевых участков: при возникновении вертикальных деформаций [мм] изделия из-за сил сжатия рекоутер может сталкивается на своем пути с последним рабочим слоем.

- Линия усадки: также из-за сил сжатия может случиться, что наносимый слой испытывает «усадку» по всему поперечному сечению, печатая видимые линии сжатия по бокам.

- Деформация: величина деформации в направлении приложенной силы, деленная на начальную длину материала. Дает коэффициент удлинения материала при растяжении.

- Напряжение: физическая величина $\left[\mathrm{H} / \mathrm{M}^{2}\right]$, которая представляет силу на единицу площади в окружении материальной точки на реальной поверхности или изображении сплошной среды.

\section{Выводы}

Установлено, что симуляция процессов печати, выполненная на платформе Magics, с помощью разбивки модели на воксельную структуру дает возможность аналитической оценки напряжений и деформаций, возникающих при различных условиях построения изделий по SLM-технологии без затрат ресурсов.

\section{Литература}

1. Стерин И.С. /Машиностроительные материалы. Основы металловедения и термической обработки/ Уч. Пособие. - СПб.: Политехника, 2003.-344 с. ISBN 5-7325-0636-5 
SIMULATION OF THE INFLUENCE OF RESIDUAL VOLTAGES AND SLM

TECHNOLOGY PARAMETERS ON FORMING A BOUNDARY AREA FROM A HEAT RESISTANT NICKEL ALLOY INCONEL 718

Adjamsky Sergey, Kononenko Ganna, Podolskyi Rostislav

Abstract. Selective laser melting (SLM) is an additive manufacturing technology in which parts can be manufactured using a laser with complex geometry and high mechanical properties. However, the optimal technological parameters of the SLM process for metallic materials are difficult to predict. The results of a universal and simplified model are presented for predicting the energy density in the region of the boundaries of a metal part from Inconel 718 , to prevent deviations in the geometry of the part based on the relationship between the density of the supplied specific energy and its absorption during the process.

Keywords: ADDITIVE MANUFACTURING, LASER, GEOMETRY, SIMULATION, INCONEL 718.

\section{References}

1. Sterin I.S. /Mashinostroitelnyie materialyi. Osnovyi metallovedeniya i termicheskoy obrabotki/ Uch. Posobie. - SPb.: Politehnika, 2003.-344 s. ISBN 5-7325-0636-5. 